\title{
Conflito social e movimento estudantil no Chile
}

Social conflict and student movements in Chile

\author{
Fernando de la Cuadra
}

\section{Excursus teórico/histórico acerca do conflito na América Latina}

A sociologia atual continua enfrentando um dos seus dilemas teóricos mais importantes, qual seja, o de pensar a sociedade em torno do consenso ou em torno do conflito. Para os funcionalistas norte-americanos, e sua concepção de sociedade como um todo integrado que se compõe de estruturas articuladas e interdependentes, a noção do acordo ou consenso torna-se fundamental para a sobrevivência e manutenção da própria estrutura social. Nesse sentido, para ter uma existência prolongada no tempo, tanto as diversas instituições de uma sociedade (sistema político, família, religião, sistema educativo) como seus mem-

Fernando Marcelo de la Cuadra é sociólogo formado pela Universidade do Chile, ex-professor do Mestrado em Estudos Sociais e Políticos Latino-Americanos da Universidade Jesuíta Alberto Hurtado, em Santiago, e doutorando do Programa de Pós-Graduação de Ciências Sociais em Desenvolvimento, Agricultura e Sociedade da UFRRJ (fmdelacuadra@gmail.com).

Artigo recebido em 18 de junho e aprovado para publicação em 16 de agosto de 2008.

Estudos Históricos, Rio de Janeiro, vol. 21, nº 42, julho-dezembro de 2008, p. 173-194. 
bros individuais devem trabalhar em completa harmonia visando à obtenção de fins comuns.

Essa teoria é negada pelos chamados teóricos do conflito, que consideram que as sociedades possuem no seu interior uma variedade de lutas, tensões e divisões entre seus membros e partes. Para esses autores, os pensadores funcionalistas só consideram uma vertente da sociedade: aquela que acredita que na vida social há sempre harmonia e acordo. Ao contrário, segundo os teóricos do conflito, é completamente ilusório pensar que as pessoas têm de viver amigavelmente umas com outras a maior parte do tempo, pois mesmo quando não se produzem confrontos diretos e abertos continuam existindo profundas divisões de interesses que, num determinado momento, podem dar lugar a conflitos ativos (Dahrendorf, 1959).

Esse debate entre os partidários do consenso e os do conflito é de certa forma uma síntese geral de outras trajetórias teóricas das quais eles são tributários. Por exemplo, a corrente funcionalista que sustenta o consenso é influenciada pelas concepções organicistas do século XIX, nas quais a sociedade era pensada como um corpo biológico-social formado por partes ligadas de modo indissolúvel. Essa perspectiva demonizava todas aquelas condutas que se definiam como atentatórias ao bom funcionamento do corpo social, servindo de argumento para que as oligarquias no poder reprimissem qualquer tipo de dissidência política.

De fato, só com isso já fica demonstrado como o conflito faz parte dos processos políticos e tem sido uma constante na realidade regional. Nesse sentido, a concepção do conflito não poderia estar ausente do pensamento social latino-americano. Mais ainda, poder-se-ia dizer que ela é intrínseca à construção das ciências sociais na região. As diversas variáveis teóricas e interpretativas dessa realidade se transformaram posteriormente no grande aporte da América Latina ao pensamento social mundial. E esse conhecimento foi elaborado a partir da própria constatação do conflito, presente em nossas sociedades desde a empresa colonizadora.

Já nos albores da constituição dos Estados nacionais latino-americanos, a pergunta que se colocou foi: que tipo de sociedade é preciso construir para o desenvolvimento e o progresso das nações do continente? Duas concepções, dois modelos de sociedade surgiram dessa interrogação. De um lado, uma concepção liberal-conservadora que assumiu uma visão orgânica e funcional da sociedade. De outro, um pensamento progressista e socialista que procurou entender a dinâmica das sociedades latino-americanas a partir de uma matriz que considerava o conflito como um aspecto relevante dessa dinâmica.

Nos debates em torno dos rumos da ordem econômico-social a ser construída logo após a independência, o positivismo e sua concepção de ordem e pro- 
gresso influenciaram "todo o debate teórico a respeito da natureza dos conflitos e das crises sociais” (Roitman, 2000: 165). Porém, com a constituição dos grupos oligárquicos, tornou-se visível a fragilidade da própria idéia de "consenso", à medida que surgiam lutas intestinas dentro das mesmas oligarquias que instauraram o dito "consenso". Esse fenômeno foi especialmente expressivo no caso do caudilhismo novecentista, em que a função dos chefes nacionais consistia principalmente em agir como mediadores e neutralizadores de disputas entre os diversos grupos em confronto.

A consagração do pensamento positivista pressupunha entender as sociedades como um agregado de interesses diversos que, no entanto, conseguiam alcançar um ordenamento estável, harmônico e permanente, hierarquicamente estratificado e politicamente legitimado por um contrato moral. As transformações decorrentes desse tipo de ordenamento seriam, portanto, um produto da mera evolução dessas sociedades. ${ }^{1}$

No entanto, a mudança também pode ser pensada como algo mais que a mera evolução das nossas sociedades. Sob a influência do pensamento socialista que começou a se expandir pelo mundo a partir da Revolução Russa, as origens do conflito social já não eram endossadas como parte das "disfunções" sociais, mas começaram a ser buscadas nas relações sociais de exploração existentes numa sociedade de classes. A partir do século XX a concepção organicista e funcional da sociedade perdeu força para uma visão que concebia o conflito como parte do processo histórico e da estrutura social de nossos países. Assim, surgiu uma geração formada nas lutas antioligárquicas e reformadoras que foram se incorporando nas arenas políticas: a idéia de ruptura e mudança social tornou-se então relevante. A noção dos conflitos e das crises sociais não só foi incorporada no debate acadêmico das ciências sociais, mas sobretudo foi integrada como fator fundamental nos marcos interpretativos da dinâmica socioeconômica e nos modelos de desenvolvimento a serem implementados na região.

Posteriormente, os conflitos e as crises iriam conformar os diversos tipos de dominação que se implantaram na região. Com a teoria da modernização, pensar a institucionalização da mudança através do processo de transição das sociedades tradicionais para as sociedades modernas representou uma forma de refletir sobre a dinâmica dos conflitos e das crises do continente. Sua existência foi considerada parte do processo modernizador das estruturas oligárquicas e tradicionais que entraram em decadência com a própria crise do modelo de desenvolvimento impulsionado por essas classes: o colapso do Estado oligárquico-liberal.

Se Germani e os teóricos da modernização reconheciam a possibilidade do conflito, o contexto da Guerra Fria e das zonas de influência provocou a polarização das ciências sociais da época. A dimensão da analise teórica dos 
conflitos ficou delimitada pela dualidade socialismo versus capitalismo. Porém a idéia do desenvolvimento de nossas sociedades vinculou-se fortemente à própria existência do capitalismo como modo de produção hegemônico e às suas modalidades históricas. A partir dessa definição se pensou a realidade regional inserida numa dinâmica contraditória e em permanente mudança. Daí surgiram diversas escolas e perspectivas teóricas aglutinadas em torno do chamado pensamento crítico, a saber: o modelo centro-periferia, a sociologia do subdesenvolvimento, o desenvolvimento desigual e combinado, a teoria da dependência, os enfoques sobre marginalidade, o colonialismo interno etc. Esses foram alguns dos marcos interpretativos mais relevantes produzidos na região a partir dos anos 1950 .

Nesse esforço de interpretação da realidade latino-americana, ganhou especial relevância o papel desempenhado pela Comissão Econômica para a América Latina (Cepal). Claro está que a Cepal não propôs desde o início a ruptura e a mudança do modo de produção capitalista, mas preocupou-se em elaborar uma resposta com o seguinte conteúdo: como elevar o atraso produtivo e cultural das sociedades latino-americanas até um patamar mais avançado de desenvolvimento. Ainda que no início os teóricos cepalinos tenham experimentado a influência exercida pelo enfoque da modernização e certa leitura neo-evolucionista, ${ }^{2}$ uma das principais teses desenvolvidas pela Cepal afastou-se dessa teoria na medida em que começou a conceber o processo de (sub)desenvolvimento latino-americano como determinado pelas relações centro-periferia.

Essa premissa supunha que o capitalismo se diferenciava em dois blocos regionais que interagiam: o centro, que possuía uma estrutura homogênea e diversificada, e a periferia, com uma estrutura heterogênea e especializada. Heterogênea, porque coexistiam setores com técnicas avançadas provenientes dos centros e setores com atraso tecnológico e baixa produtividade. A estrutura produtiva da periferia era ainda especializada, uma vez que se beseava quase que exclusivamente na produção primária.

O conceito centro-periferia trouxe consigo outra grande contribuição cepalina: a deterioração dos termos de troca. Essa noção postulava que a relação entre os preços dos bens industriais exportados pelos países centrais e os preços das matérias-primas importadas por eles mesmos tendia a diminuir persistentemente a longo prazo, o que implicava que o poder de compra de bens industriais de uma unidade produtora de bens primários de exportação caía ao longo do tempo, produzindo-se uma deterioração cumulativa do poder aquisitivo da renda gerada pela produção primária.

Em sua versão original, o propósito do modelo estruturalista cepalino consistia numa mudança da estrutura produtiva, assim como demográfica, dis- 
tributiva e ocupacional dos países periféricos, de modo a pôr fim a seu caráter subordinado. Nas palavras de Raúl Prebisch:

A estrutura social prevalecente na América Latina opõe um sério obstáculo ao progresso técnico, e por conseguinte ao desenvolvimento econômico e social [...] essa estrutura entorpece consideravelmente a mobilidade social e se caracteriza pelo privilégio na distribuição da riqueza. (Prebisch, 1971: 4)

Posteriormente, no calor do contexto de formação dos blocos e da Guerra Fria, a visão estruturalista do enfoque centro-periferia foi adquirindo uma perspectiva mais radical, de influência marxista, em que essa dualidade era percebida como um processo inerente à própria lógica do capitalismo. Surgiu então um novo arsenal teórico tendente a mostrar a necessidade da mudança social e de articular a sociedade em torno de objetivos como a democracia plena e o desenvolvimento econômico e social. No bojo desse debate emergiu a teoria da dependência, cujo postulado principal era que a condição de subdesenvolvimento dos países latino-americanos seria conseqüência das relações históricas que foram se estabelecendo entre as antigas metrópoles e suas respectivas colônias desde a época do descobrimento. Portanto, a vinculação das economias periféricas com o mercado mundial realizar-se-ia em termos "coloniais", informando o caráter subordinado e dependente dos países subdesenvolvidos e latino-americanos em particular. Esse processo representaria não só um vínculo entre os países dependentes e as metrópoles, mas também a forma como se expressava concretamente tal relação. Quer dizer, ao considerar a situação de dependência, essa análise tornava explícito o fato de que o modo de integração das economias nacionais ao mercado internacional pressupunha formas definidas e diferentes de inter-relação dos grupos sociais de cada país entre si e com os grupos externos (Cardoso e Faletto, 1970).

Diferente da noção centro-periferia, o enfoque da dependência dava maior importância aos fatores político-sociais. Isso implicava pensar na articulação de interesses internos e externos e no papel desempenhado pelos grupos privilegiados de cada país na configuração da estrutura de dominação e das formas de estratificação que condicionavam os mecanismos e os tipos de controle que se exerciam sobre o sistema econômico. O exercício desse poder punha em confronto, portanto, as classes que controlavam e organizavam a produção e o consumo e as que se opunham a essa dominação.

A força interpretativa da realidade regional decorrente dessa análise influiu de maneira significativa na consolidação de uma teoria que ganhou nume- 
rosos adeptos. Nesse marco, o pensamento social latino-americano incorporou cada vez com maior força a noção do conflito como parte da própria dinâmica das sociedades. Assim, os cientistas sociais vinculados à Cepal chegaram a efetuar a autocrítica do modelo estruturalista de Industrialização Substitutiva das Importações (ISI), destacando os limites de um projeto de desenvolvimento nacional autônomo.

As sociedades latino-americanas iniciaram uma fase de crescimento das forças populares exacerbando um conflito presente desde a colonização, mas que não se tinha manifestado com a força que lhe conferiu o triunfo da Revolução Cubana. Os estudos sobre o conflito e as crises já foram o resultado de enfrentamentos teóricos entre os defensores de uma modernização capitalista e de uma racionalidade política e os que propunham a superação e a transformação das estruturas sociais que sustentavam a exploração e o domínio capitalis$\mathrm{ta}^{3}$

O golpe militar de 1964 no Brasil inaugurou uma etapa de regimes militares (burocrático-autoritários na terminologia de O’Donnell) que abortou de maneira dramática os projetos de transformação regional e, mais ainda, substituiu a noção de conflito, que estava no centro das contradições, por concepções organicistas, que visualizavam a sociedade como um corpo social coeso, harmônico e interdependente.

Tal como assinala Roitman:

As concepções organicistas são revividas para fundamentar a nova ordem social. O caráter desagregador de ideologias consideradas subversivas e estranhas à própria essência latino-americana serviu de pretexto para a repressão e perseguição de idéias e pessoas. Assim, desqualificar o pensamento crítico e considerá-lo como fator engatilhador da violência política e social foi o argumento mais utilizado pelas ditaduras militares para impor um novo modelo de ordenamento político, social e econômico. Nesse modelo, o conflito estava superado, ou melhor, não estava permitido. (Roitman, 2000: 169)

Com o processo de redemocratização iniciado na região a partir dos anos 1980, elevaram-se vozes que, influenciadas pelas perspectivas funcionalistas, enfatizavam o caráter harmônico e consensual da transição democrática. A própria Cepal, antes palco importante do debate sobre o conflito social e econômico na realidade latino-americana, inaugurou uma nova fase do seu pensamento com um documento em que estabelecia uma espécie de renúncia a todos os postulados que marcaram seu pensamento nos anos 1940 e 50 . A ausência da temática do 
conflito apareceu nessas elaborações posteriores como uma forma de estabelecer a diferença.

Num texto da nova etapa, a Cepal (1990) concluía que durante os anos 1980 a região passou por uma "aprendizagem dolorosa" e que, portanto, a experiência acumulada demonstraria que as divergências entre os diversos setores deveriam ser superadas por meio do acordo e da conciliação. Ou seja, no âmbito político-social, essa aprendizagem parecia supor que o fim dos governos democráticos anteriores ao ciclo de ditaduras militares das décadas de 1960 e 70 se devera fundamentalmente ao fato de que as instituições haviam sido superadas pela irrupção de demandas dos diversos setores da população, as quais não tinham podido ser processadas pelo sistema político. A falta de consenso levara ao colapso a institucionalidade democrática, dando lugar a crises de governabilidade que desembocaram nos regimes autoritários.

Portanto, pode-se pensar que a Cepal também incorporou a noção de que os conflitos e as crises decorrentes na maioria dos países da região foram resultado do avanço das demandas e "excessos" das forças progressistas, levando a um esgotamento da ordem democrática. Logo, a redemocratização do continente implicaria, segundo a Cepal, incorporar a lição da aprendizagem dolorosa, ou seja, eliminar ou limitar a dimensão conflitiva de nossas sociedades.

A partir dessa conclusão, a Cepal utilizaria permanentemente em seus documentos os conceitos de concertação, cooperação e consenso entre os diversos atores sociais e agentes econômicos, excomungando de suas análises noções tão significativas como as de centro-periferia, dependência, estrutura de dominação, poder, crise e conflito social. O abandono de uma proposta social e política, além da debilidade do neo-estruturalismo, revela uma opção ideológica que sem dúvida adultera as intenções de Prebisch quando expôs seu pensamento em Capitalismo periférico (Prebisch, 1981).

É indubitável que os diversos governos que viveram a experiência "traumática" das ditaduras militares sentiram-se inclinados a adotar uma postura mais conciliadora e consensual a respeito do devir das diversas sociedades e das formas de resolver as disputas políticas. Como veremos a seguir, isso é particularmente válido no caso chileno, em que finalmente se impôs uma espécie de conservadorismo sistêmico, sustentado no temor de qualquer forma de demanda ou expressão que possa sair dos marcos institucionais e disciplinados definidos pela chamada democracia dos consensos.

\section{A democracia minimalista da Concertación}

A chegada ao poder em 1990 do primeiro governo da Concertación de Partidos por la Democracia (CPD) se fez depois de 17 anos de ditadura militar. A tran- 
sição democrática não se deu num contexto de crise econômica - como no caso de outros países da região -, mas o novo governo que tomou posse em março daquele ano não somente herdou uma grande massa de excluídos deixada pelo modelo econômico neoliberal implementado de forma pioneira pelos militares, como ficou refém de um emaranhado de restrições institucionais impostas pela Constituição vigente, aprovada em plena ditadura (1980). Nessa Carta tiveram origem os enclaves autoritários presentes no sistema político, a saber, senadores designados, sistema eleitoral binominal, Conselho de Defesa do Estado, inamovibilidade dos comandantes-em-chefe das Forças Armadas etc.

Ou seja, ainda que o Chile não apresentasse, stricto sensu, problemas de governabilidade (legitimidade, eficácia e eficiência), mostrou os limites impostos pelo tipo de passagem empreendido, chamado de transição pactuada. Esse tipo de transição representou a consagração de uma política de negociação de "consensos" que levou os diversos atores políticos a buscar acordos pontuais sobre temáticas específicas, e de forma muito gradual, negando espaço para a discussão de aspectos substantivos para a construção de uma democracia plena.

Portanto, já desde o início da transição democrática, ficaram evidenciadas as dificuldades do governo - e da coalizão de partidos que lhe dava apoio para desmontar a estrutura institucional e a Constituição herdada dos militares. Essa atitude teria sua origem na "aprendizagem traumática" da classe política chilena, que optou por uma saída negociada e instrumental, livre das dimensões de confronto e dos estigmas autoritários do passado. A síntese do ideário segundo o qual se deve avançar para a plena democracia de forma "lenta e gradual" (como costumavam afirmar os generais brasileiros) obedeceu a uma atitude negativamente negociadora, na qual se está, finalmente, disposto a abdicar de valores caros à democracia, como a representação das minorias, a participação ampla da cidadania, a subordinação das Forças Armadas ao poder civil etc. Esse estilo de fazer política - segundo os termos definidos pela transição -, que procura a consagração de acordos harmônicos e ordenados, recebeu o nome de democracia dos consensos.

A aversão a um enfrentamento decorrente da aplicação de um novo projeto nacional contribuiu poderosamente para não impulsionar desde o começo do governo Aylwin as reformas constitucionais necessárias para superar os enclaves autoritários. Assim, a Concertación decidiu superar as "feridas" do passado para dedicar-se à tarefa de construir uma nova nação, com base nos valores da reconciliação e do perdão, tal como vinha sendo sugerido por alguns setores da Igreja Católica.

Os diversos governos da CPD não somente incorporaram esse roteiro de conciliação e reencontro, mas, no seu bojo, consagraram também um projeto mi- 
nimalista de pequenas transformações econômicas, políticas e sociais para o país. Na sua totalidade, o projeto neoliberal não sofreu profundas alterações, salvo algumas ações específicas e pontuais, que concederam ao Estado um papel de maior relevância. Ainda que reconhecendo o esforço realizado pelos dois últimos governos socialistas da Concertación para mudar o padrão dominante, é preciso salientar também que as forças democráticas não conseguiram romper com os entraves autoritários e as posturas intransigentes de um setor proeminente da direita política, que exerce uma ferrenha oposição às reformas do sistema político, às mudanças do regime tributário e, por último, à universalização do modelo de proteção social.

Nesse contexto, no âmbito político destacam-se a vigência da Constituição promulgada em plena fase ditatorial (1980) e a existência do sistema binominal, pelo qual se institucionaliza a ausência de representação dos partidos de menor tamanho. Não obstante a atual presidente ter assinalado a possibilidade de convocar um plebiscito para dirimir esse problema que tolhe a democracia, até agora não se vislumbraram os termos concretos nos quais se realizaria esse plebiscito, nem foram estabelecidos prazos na agenda do governo.

Com respeito à esfera das políticas sociais, as últimas administrações de Lagos e Bachelet tampouco têm respondido às grandes expectativas que tinha a maioria do povo chileno. Ainda que o gasto social tenha aumentado no último qüinqüênio, ele se orienta pelo princípio da focalização, mantendo uma parte importante do funcionamento das áreas de educação, saúde, previdência, moradia e serviços sociais em geral nas mãos do setor privado, reforçando o caráter neoliberal de tais políticas, que só vêm sofrendo mudanças visando à sua maximização, e não procedendo à sua reestruturação (Angelcos, 2008; Claude, 2008; Moulian, 2006; Sant'Anna, 2006).

Resumindo, poder-se-ia dizer que, a despeito dos esforços efetuados no âmbito das reformas políticas e sociais, os sucessivos governos da Concertación de Partidos por la Democracia não têm conseguido marcar uma diferença significativa com relação aos feitos do governo militar, principalmente em matéria econômica: manutenção dos equilíbrios macroeconômicos, estabilização monetária, geração de superávit fiscal, abertura para o exterior, aproveitamento das vantagens comparativas, desregulação, regime impositivo regressivo, estímulo ao lucro das empresas, flexibilização do trabalho, ter- ceirização etc.

A falta de uma ênfase na resolução dos problemas sociais torna visível a persistência da desigualdade social e o vácuo deixado pelos governos concertacionistas, criando um fato tanto paradoxal quanto inédito: a façanha de pôr nas mãos da direita a bandeira da justiça social como sua principal proposta para o país. Foram precisamente os fracassos mostrados por esses governos em superar os problemas de eqüidade e de integração que acabaram por mobilizar os estu- 
dantes secundários, num primeiro sinal de alerta para a gestão de Michelle Bachelet.

\section{A marcha dos pingüins: uma breve história}

No período da transição democrática iniciado em 1990, o movimento estudantil secundarista atribuiu-se principalmente a tarefa de reconstruir seus grêmios no interior dos estabelecimentos educacionais, devido ao férreo controle que as direções dos liceus exerceram sobre eles nos anos da ditadura militar. Mas essa reconstrução não recomeçou do zero. $\mathrm{O}$ movimento estudantil mostrou bastante vitalidade nos anos da maior repressão do regime de Pinochet, acumulando uma rica experiência de participação no processo de luta pela recuperação da democracia no país.

Depois de algumas manifestações de certa relevância nos últimos anos do governo Lagos, os estudantes secundários reiniciaram, no final de abril de 2006, marchas e protestos exigindo a gratuidade do passe escolar (vale transporte) e a diminuição do valor da inscrição na Prova de Seleção Universitária (PSU). No início das mobilizações calculava-se que a participação chegava a $10 \mathrm{mil}$ estudantes. Diante desse cenário, o governo reagiu da pior forma: começou a desqualificar os manifestantes, revelando, no conjunto de suas atitudes e atos, certa insensibilidade para enfrentar o conflito. Membros do governo definiram as mobilizações como produto de mentes imaturas de jovens rebeldes e prognosticaram que as sucessivas convocatórias só seriam acatadas por um grupo bem minoritário. Não só desconsideraram a legitimidade das reivindicações dos estudantes, mas também criminalizaram seus atos, chamando-os de violentos ou baderneiros, discurso que foi amplamente difundido e apoiado pela imprensa conservadora.

A partir dessa visão, criaram-se as condições para justificar a ação das forças policiais que reprimiram ferozmente as manifestações de rua, com o consentimento ou a omissão do Executivo. Desse modo, o diagnóstico feito pelas autoridades e amplificado pelos meios de comunicação era que o movimento estudantil e as mobilizações representavam meramente uma rebeldia juvenil, e em alguns casos uma desculpa para delinqüir (os encapuzados), e que os dirigentes estavam sem capacidade de organização e legitimidade para deter os atos de vandalismo verificados nas principais cidades. Após 10 dias de manifestações maciças e do recrudescimento da repressão policial, com centenas de estudantes detidos, o conflito explodiu no interior do governo, que, como medida de emergência para sair da crise, determinou o afastamento do chefe da Polícia Metropolitana. 
Durante o transcurso do mês de maio os estudantes mudaram de tática. No início desse mês as mobilizações se realizavam na rua, mas, devido à desordem crescente e principalmente ao grande número de feridos e detidos, a Assembléia Coordenadora dos Estudantes Secundários (Aces) resolveu passar a ocupar os estabelecimentos de ensino. Dessa forma, o movimento recobrou força inusitada e os estudantes paralisaram suas atividades escolares, com mais de $100 \mathrm{mil}$ alunos entrando em greve e em torno de 100 colégios ocupados. Segundo informações da imprensa, em fins desse mês a rebelião dos jovens se estendeu por todo o país e recebeu também o apoio de outros setores (estudantes universitários, professores, profissionais), chegando a mobilizar aproximadamente um milhão de pessoas, no maior protesto estudantil de que se tem memória nos últimos anos. ${ }^{4}$ Finalmente, e devido ao fracasso nas conversações com o governo, os estudantes decidiram convocar uma jornada de paralisação nacional para o começo de junho (dia 5), à qual aderiram os estudantes universitários e diversas organizações e categorias profissionais.

Nesse momento produziu-se uma virada estratégica nas reivindicações dos estudantes. À medida que o conflito começou a se alastrar pelo país e que novos atores foram se somando ao movimento, ampliaram-se as demandas por reformas de caráter estrutural, como a reformulação da Jornada Escolar Completa (JEC) e a extinção da Lei Orgânica Constitucional do Ensino (Loce) promulgada (literalmente) no último dia do regime militar (10/3/1990). Essa lei permitiu, entre outras coisas, que a educação pública fosse transferida dos liceus sob o controle do governo central, capaz de manter a boa qualidade do ensino, para os municípios. A ineficácia e a falta de recursos demonstradas pelos governos locais agiram diretamente em detrimento da qualidade do ensino das escolas municipais, sobretudo em comparação com os colégios particulares. Por esse motivo, um dos principais slogans que surgiu no calor das mobilizações foi: "Exigimos maior intervenção do Estado no sistema educacional, a educação é um direito e não um privilégio". Ele representava claramente o apelo dos estudantes por uma educação gratuita e de qualidade, em vista da enorme brecha existente entre o ensino privado e o municipal. ${ }^{5}$

A relevância e a dimensão adquiridas pelos protestos colocaram em xeque o governo, que finalmente teve de negociar com os "revoltosos" e convidá-los a participar da formação de um Conselho Assessor Presidencial para a Qualidade da Educação, encarregado de elaborar uma proposta capaz de conciliar os diversos setores em conflito, avaliando a pertinência de se fazer mudanças na Lei Orgânica Constitucional do Ensino. Esse Conselho foi integrado por 74 membros, sendo que 12 deles eram representantes dos estudantes. No entanto, como foi exposto por um dirigente secundarista: "Em torno de 70 por cento dos membros 
'adultos' do Conselho não compartilham nossas idéias" (Ferretti e Massardo, 2006: 6). O Conselho também foi questionado em repetidas oportunidades tanto pelos estudantes como por outros setores da sociedade, em parte pelo excessivo número de membros, que comprometia sua capacidade operativa, mas sobretudo pela desídia e a indolência com que muitos integrantes da comissão enfrentaram os trabalhos necessários para elaborar a proposta final.

Segundo os estudantes, a falta de compromisso de muitos membros do Conselho, e especialmente a ausência de perspectiva com relação ao documento final, levou à retomada das mobilizações no mês de outubro de 2006, dias depois que se deu a conhecer o informe sobre o andamento dos trabalhos do Conselho.

Esse novo surto de agitação secundarista deveu-se (nas palavras dos dirigentes) ao descontentamento que provocou entre os estudantes o precário progresso nas propostas. No entanto, a tática utilizada em maio, que consistira fundamentalmente na ocupação dos estabelecimentos educacionais, teve que ser revertida pela força dos fatos. Essa segunda onda de protestos foi marcada pela entrada das forças policiais nos liceus e colégios e pelo desalojamento dos alunos. Muitos foram detidos, ameaçados ou expulsos dos colégios, diante do que a assembléia de estudantes decidiu ocupar novamente as ruas para expressar suas demandas. A mudança de tática teve conseqüências imediatas no tocante ao grau de confrontação gerado entre os estudantes e as "forças da ordem", reiterando-se as cenas de violência e repressão já advertidas em maio.

Poucos dias antes de vir à luz o informe final do Conselho, os estudantes secundários - logo seguidos pelos universitários e professores - decidiram " $b a$ jarse" do documento, quer dizer, não assinar a versão final que seria entregue à presidente Bachelet no dia 11 de dezembro. $O$ argumento era simples e direto: os alunos não se sentiam representados pelos resultados expostos no texto final, que, segundo eles, acabava por consagrar a visão mercantil da educação.

No curso do presente ano de 2008, os estudantes têm retomado as mobilizações. ${ }^{6}$ Depois de realizar a ocupação de aproximadamente 200 liceus, colégios e universidades, decidiram ocupar a sede central de dois partidos da Concertación (PPD e PS). A medida foi tomada um dia depois que o governo evacuou 40 estabelecimentos educacionais e repôs na agenda legislativa a urgência da aprovação, na Câmara dos Deputados, da Lei Geral de Educação (LGE). O porta-voz da Federação de Estudantes da Universidade do Chile afirmou que aquela era "uma ocupação pacífica e temporária com poucas pessoas". Com ela, os jovens rejeitaram o pacto entre a Concertación e os partidos de direita (congregados na Aliança por Chile) que dera vida à LGE e pressionaram os partidos cujas sedes foram ocupadas para que se pronunciassem a favor de suas exigências. "Nossos reclamos são por uma educação pública gratuita em todos os níveis, pelo fim da 
municipalização, a eliminação da educação (privada) subvencionada, e o co-governo efetivo", informaram os estudantes num comunicado.

Em síntese, a crítica dos estudantes experimentou uma importante mudança, ao passar de reivindicações pontuais (passe livre escolar, isenção da taxa PSU) para um questionamento do modelo como um todo, chamando a atenção para o fato de se conceber a educação como uma atividade lucrativa, tema que nunca foi incorporado ao relatório do Conselho para a Melhoria da Qualidade da Educação. Por último, existe um amplo consenso de que os recursos públicos não devem destinar-se à iniciativa privada, a qual não somente pode gerar uma perda dos valores cívicos e republicanos, mas afeta a própria qualidade do ensino através de instituições cuja principal finalidade consiste na obtenção de lucro.

\section{Buscando entender a resposta do governo}

A explosão das mobilizações estudantis que se iniciaram no mês de abril de 2006 colocou em questão a capacidade da recém-empossada administração de lidar com o conflito. Num primeiro momento, a reação do governo foi negar o conflito e atribuir-lhe um caráter de expressão natural de rebeldia da "molecada", que se extinguiria também naturalmente com o passar dos dias. No entanto, como é quase unanimidade nos dias de hoje, o tom displicente da autoridade e o trato especial que deu aos estudantes secundários (garotos sem experiência) se cristalizaram finalmente numa errática combinação de política repressiva e paternalista, provocando, como se sabe, o efeito contrário do esperado: o acirramento do conflito.

A aversão expressada pela então recém-empossada administração diante de seu primeiro grande conflito derivou inicialmente na negação deste. A tese do apaziguamento do conflito através de causas naturais e seu posterior esquecimento por parte dos estudantes e da comunidade nacional fizeram com que o governo, em lugar de assumir a iniciativa e registrar as reivindicações estudantis, ficasse esperando que o conflito se resolvesse por si mesmo, como se aqui também pudesse operar a "auto-regulação" do mercado.

Expostos o conflito e a reação das autoridades diante das mobilizações, surgem imediatamente algumas perguntas: por que um governo socialista que se sustenta no discurso da cidadania e da participação acabou reprimindo com violência policial os estudantes? O que explica essa espécie de paralisia decisória que teve o governo diante de um conflito já declarado? Como diversas autoridades enfrentaram o conflito suscitado de maneira tão errática? A seguir tentaremos refletir sobre essas questões, a partir de algumas chaves explicativas que têm 
sido formuladas por diversos especialistas e que nos permitem entender, ainda que tentativamente, a conduta assumida pelas autoridades.

\subsection{A diferença de gerações}

Uma primeira e mais óbvia indicação que podemos tirar da resposta do governo diante das expressões do movimento secundarista é que a sua forma de compreender o conflito revela uma profunda distância, em termos de concepções e visões de mundo, entre as autoridades, as instâncias decisórias de políticas públicas e os estudantes. Essa distância se traduz na negação aos secundaristas da qualidade de sujeitos políticos e interlocutores válidos, e com isso, na incapacidade de entender a ação coletiva por eles empreendida.

Essa deficiência demonstrada pelas autoridades do governo e pela classe política não é exclusividade delas. A percepção dos jovens como "moleques" que gostam de provocar barulho é também compartilhada por outros setores da sociedade chilena. Se é verdade que os jovens desempenharam um papel importante nas lutas pela democratização do país, através de inúmeras manifestações e protestos, na fase de transição democrática esse segmento foi estigmatizado, por parte importante da sociedade chilena, como um ente passivo e apático. Dessa maneira, virou lugar-comum dizer que os jovens da era pós-Pinochet eram um grupo anódino de sujeitos que "não estavam nem aî" para o que acontecia no país e não demonstravam nenhum interesse pelas questões sociais e por participar nos assuntos políticos. O indicador indiscutível de tal afirmação era a expressiva quantidade de jovens que não estavam inscritos nos registros eleitorais: possuíam título de eleitor um milhão e meio de jovens, que representavam quase $70 \%$ do eleitorado com menos de 25 anos (18-25). ${ }^{7}$

A comprovação estatística do desinteresse eleitoral foi lida como sintomática da indiferença política dos jovens, e diversos setores sociais e políticos consideraram que a solução para o problema da participação estaria na alteração (inversão) do sistema até então vigente, ou seja, em fazer o alistamento eleitoral de forma automática (no momento de obter a carteira de identidade) e em transformar o voto em um ato voluntário. Se os jovens estiverem alistados, a lógica indica que eles irão votar, por uma espécie de inércia cidadã. Outra leitura dessa apatia juvenil foi interpretar que a própria rebeldia sintomática dessa fase da vida encontrava-se submergida pelo apelo a condutas que procuram o prazer individual ou de pequenos grupos (o chamado hedonismo da vida contemporânea). No entanto, sabe-se que essa abulia é aparente, e diversos estudos empíricos têm constatado que os jovens querem participar, mas não se vêem interpretados pelos partidos políticos e pela classe política em geral (Aguilera, 2006; INJUV, 2003 e 2007). A ausência de alistamento não é um fiel reflexo do "estado de espírito" dos jovens, mas sim uma 
forma de expressar a insatisfação com a maneira como a classe política e os partidos têm conduzido o processo de transição democrática. ${ }^{8}$

Seguindo uma interpretação similar, José Joaquín Brunner argumenta que o que as mobilizações dos jovens revelam é, antes de tudo, "um mal-estar dessa geração com a cultura estabelecida, especialmente com aqueles aspectos mais vinculados a suas instâncias formativas" (Brunner, 2006: E3). Os temas decorrentes desse tipo de preocupação, segundo o especialista, são muito vastos e refletem desde a educação até os padrões de consumo, a família, a moral, a religião, a estética, os meios de comunicação e as tecnologias do conhecimento. Mistura de rupturas com a herança de uma sociedade amedrontada e marcada pelo trauma ditatorial, essa juventude é também produto das lutas sociais e das tentativas de mudanças da história política nacional, que, como bem salienta Brunner, no fundo representam uma homenagem à cultura política de seus pais, paulatinamente perdida no marasmo da vida moderna, no esforço desmedido e na luta cotidiana pela sobrevivência.

\subsection{A perspectiva economicista}

Uma segunda perspectiva de análise da resposta das autoridades se situa na dimensão econômica do problema. Quer dizer, para os funcionários do governo, a emergência do conflito se deveria principalmente à ineficiente e imperfeita alocação de recursos destinados à educação, ou seja, à deficitária relação custo/benefício. Para os economistas defensores dessa idéia, o governo deveria maximizar o uso dos recursos alocados na execução da política social, e na educação, de forma que o resultado da matriz insumo/produto fosse sempre positivo. O critério geral que orienta esse ponto de vista é que os alunos são concebidos como um output do sistema, o produto necessário, em termos de formação profissional e capacidades técnicas, para que nossas empresas se tornem mais eficientes e capacitadas a competir em melhores condições nos mercados internacionais, e para que, em decorrência disso, a economia nacional cresça estável e sadia.

A partir desse marco de análise, o problema residiria na má definição dos critérios para conferir os subsídios às escolas municipais e aos colégios particulares subvencionados, e para definir as formas de controle sobre o uso desses recursos. Também explicariam o conflito os erros cometidos na designação e entrega dos créditos e bolsas de estudos aos estudantes das universidades, que também aderiram às manifestações. A solução surge então quase simultaneamente com o diagnóstico. Se o problema reside na melhor alocação dos recursos, o Estado deve velar para que o uso dos fundos públicos destinados à educação sejam bem gastos, e para isso é preciso melhorar tanto as formas de transferência dos 
recursos quanto os métodos de fiscalização e monitoramento do financiamento destinado à política setorial de educação.

Uma crítica da visão economicista tem sido sustentada pelo filósofo Humberto Maturana. Esse tipo de leitura fez precisamente com que certas autoridades enfrentassem o conflito como um tema fundamentalmente econômico, um tema de investimento e produto. Isso, segundo ele, representa uma perspectiva reducionista e completamente equivocada. Pelo contrário, a rebelião dos pingüins tem a ver com a dor espiritual pela falta de sentido que a educação formal dá aos jovens. Assim, o fator fundamental que explicaria essa revolução dos jovens estaria na rejeição de um modelo educativo que reflete uma visão do país individualista e fragmentada. A rebelião surge precisamente porque o sistema educativo concebido durante a ditadura ressalta o caráter mercantil da educação. Numa comunidade, não são os interesses pessoais que prevalecem, mas a participação na criação de um mundo comum. No livre mercado, o que prima são os interesses pessoais. Isso seria rejeitado pelos jovens que buscam um sentido para suas vidas, que querem acreditar num projeto "em que todos se sintam partícipes da criação de uma nação onde seja desejável, digno e criativo viver" (Maturana, 2006: 21).

\subsection{A governabilidade excessiva ou hipergovernabilidade}

As explicações até agora levantadas, embora exponham o complexo dilema que o conflito social coloca, no qual se cruzam as heranças econômicas do pinochetismo (privatização do ensino) com uma real necessidade de mudança desses parâmetros, são ainda insuficientes para compreender o fenômeno na sua integridade. Uma outra tentativa de explicar a resposta do governo tem a ver com aquilo que no nosso entender se pode chamar de hipergovernabilidade. Essa noção é construída a partir da idéia de que numa "democracia de consensos" não pode haver espaço para o dissenso, sobretudo quando este é expresso por vozes não "legitimadas" como interlocutores relevantes. A existência de experiências traumáticas no passado recente fez com que significativos e conspícuos atores da arena política expressassem que o melhor é sempre evitar o conflito, visto que as chamadas frágeis democracias, que estão transitando para sua plenitude, podem vir a ser ameaçadas pela existência da ingovernabilidade.

A apreensão sentida pelo governo na participação e na explosão das demandas dos jovens pode ser entendida, em grande parte, como um produto do desmedido esmero depositado pelo governo na manutenção da governabilidade. Compartilhando essa mesma preocupação, o cientista político Daniel Campione sustenta que "toda intervenção de 'massas' (mesmo as de caráter subordinado) é vista como potencialmente perigosa para a governabilidade do sistema, que se percebe como estando ligada a uma apatia política que permitiria avançar rumo à 
utopia do Estado mínimo, o Estado modesto, fisicamente menos custoso e imunizado contra o perigo de abrigar organizações propensas a se tornar anticapitalistas ou, pelo menos, a perturbar a lógica da acumulação" (Campione, 2003: 58).

No entanto, essa preocupação com a capacidade governativa não tem o mesmo selo conservador brandido por Samuel Huntington faz já quatro décadas. Resumidamente, para esse autor, a estabilidade política de um país se rompe quando não existe um marco institucional capaz de suportar o nível crescente de demandas que fazem diversos atores sociais e políticos. Tal institucionalidade acaba sendo superada por setores que irrompem com novas reivindicações no cenário nacional, levando ao colapso do sistema democrático. Dessa forma, o problema da governabilidade da democracia aponta os limites que o sistema deve impor a seus cidadãos, para que os decorrentes "excessos" desses grupos sejam devidamente controlados pela autoridade estatal (Huntington, 1968).

A governabilidade que emerge no caso de que nos ocupamos tem um sentido mais resolutivo. $O$ governo tem se dedicado a sublinhar que os problemas da população são em sua grande maioria cobertos pelos órgãos competentes da máquina do Estado, dando a entender que todas as demandas da cidadania podem ser resolvidas por um governo "legítimo e eficiente", que não requer mobilizações da sociedade civil. Em tal caso, para alguns representantes do governo - como o ministro da Fazenda -, as pressões feitas pelos movimentos sociais poderiam afetar tanto as finanças públicas como o bom desempenho da economia, e em conseqüência exercer um impacto direto sobre o índice de risco-país. Assim colocada, a questão se apresenta como uma espécie de falso dilema entre a satisfação de necessidades imediatas e a participação cidadã, dado que esta última se torna prescindível, uma vez que as carências da sociedade são detectadas e quantificadas com antecipação e são posteriormente "tratadas" por quadros técnicos de alta competência.

A principal preocupação do Estado parece orientar-se para a sustentação da capacidade de governar estimulando os movimentos sociais a manter um "baixo perfil" na sua demanda ou ação contestadora. Diferente da noção conservadora, nesse caso não existe nenhuma intenção explícita de limitar a expressão de determinada demanda; enfatiza-se o caráter "impróprio" que ela possui, em virtude da capacidade que a autoridade tem de se antecipar às necessidades do povo e dessa forma oferecer as soluções mais rápidas e adequadas a cada situação particular. Assim, o governo está pré-munido de equipes de especialistas e de um conjunto de estudos que permitem abordar com efetividade e eficiência as carências e dificuldades que atingem a população. É a manifestação mais perversa das boas intenções. Como se o caráter da inclusão democrática da cidadania se restringisse à credencial de "beneficiários" de programas sociais, como se a dimen- 
são política dessa cidadania ficasse reduzida ao apelo social e, por essa via, plenamente satisfeita.

Ainda que no discurso oficial o governo central reconheça a importância da participação cidadã, nos fatos ela é muito reduzida. No papel, assinala-se que os cidadãos devem comparecer ativamente na execução dos diversos programas e projetos, que os sistemas de controle e de prestação de contas das autoridades representam um componente fundamental da democracia, ou que não se pode construir a democracia sem a ingerência dos cidadãos; mas na realidade os governos da Concertación pouco têm estimulado a participação efetiva - e muitas vezes incômoda-das pessoas nas diversas arenas onde ela deve se expressar. A rigor, a autoridade tem provocado o desânimo por parte dos atores para representar seus interesses, baseando-se para isso na falsa concepção de que a participação é dispensável.

Existe uma espécie de governabilidade hipertrofiada (ou hipergovernabilidade) que termina sendo uma verdadeira armadilha para os apóstolos da "ordem institucional", ao dar uma ênfase desmedida ao funcionamento das instituições democráticas como garantia da ordem social. Conseqüentemente, a abdicação do conflito como parte estruturante da sociedade e da política enuncia, sem maiores mágicas, a desconfiança do governo e seus funcionários na capacidade que têm as pessoas e as organizações de exercer com ponderação seu direito à participação e influir nas decisões políticas que afetam seu próprio destino.

\section{Reflexões finais}

Já se passaram mais de dois anos desde que o movimento estudantil secundarista iniciou as mobilizações que colocaram em xeque o governo e abriram um amplo debate sobre os problemas do financiamento, qualidade e eqüidade da educação chilena, bem como sobre o papel da juventude no futuro do país. Qual é a projeção do movimento secundarista? É difícil ter certeza sobre essa questão, mas é possível postular que, pela forma como o movimento tem-se organizado, sem estrutura definida e com um sistema de representação equilibrado e participativo, pela coerência de suas posturas e pela capacidade demonstrada para captar a adesão de diversos setores sociais, essa "rebelião dos pingüins" constitui uma importante advertência sobre os caminhos percorridos pelo modelo econômico, político e social chileno. E mais ainda, um oportuno alerta na atual cultura autocomplacente em que se encontra a sociedade nacional. Com bandeiras de luta centradas na qualidade e na eqüidade da educação, a agitação estudantil combinou ocupações, greves, passeatas, enfrentamentos, a uma grande capacidade para somar o apoio da cidadania a suas demandas. 
Assim, as mobilizações e demandas expressadas por esse grupo de jovens que não têm mais de 18 anos poderiam representar uma forma de luta contra-hegemônica que questiona o modelo educativo mercantil que ainda impera no país, e mais do que isso, interroga o paradigma neoliberal imposto pela ditadura e administrado com certa inércia pelos sucessivos governos da Concertación.

Por outro lado, a perseverança mostrada pelos estudantes em participar na elaboração de propostas que visam a solucionar o problema da educação não apenas põe em dúvida a capacidade governamental de resolver a crise educacional mediante o concurso de "experts", mas sobretudo recoloca a importância da participação política e da mobilização cidadã como valores inalienáveis da democracia.

O que virá a acontecer daqui para a frente é uma incógnita, e o conflito ainda pode se estender por muito tempo. Mas uma possibilidade talvez seja que a semente lançada por esse movimento possa significar um outro patamar para a elaboração de uma alternativa diante do modelo hegemônico em vigor, por meio de sucessivas mudanças moleculares, transformando assim sua luta particular num processo de participação geral que envolva o conjunto da sociedade chilena na construção de um projeto nacional renovado, mais eqüitativo, inclusivo e radicalmente democrático.

Notas

1. Porém, para Durkheim, a possibilidade de rupturas dramáticas não é descartada de antemão. Nesse caso, segundo ele, a existência de qualquer mudança precipitada acarretaria no seu bojo a desintegração social e a dissolução do sistema de regulação social, ou a falta de regras e normas (anomia).

2. É a perspectiva do desenvolvimento por etapas. Essa idéia evolucionista parte da caracterização do subdesenvolvimento como um problema que deve ser superado, e para isso ele tem um modelo a imitar. O pressuposto é que as sociedades atrasadas devem seguir o mesmo roteiro que as sociedades industrializadas, ou seja, percorrer as mesmas etapas pelas quais transitaram as economias desenvolvidas.

3. Os trabalhos de Pablo González Casanova e a ótima compilação de José Matos Mar (1972) representam uma clara demonstração desse esforço intelectual.

4. Cifras apresentadas por José Seoane e Clara Algranati (2006) a partir de informações da imprensa chilena.

5. Os alunos do ensino privado, ao qual se pode aceder via mercado, têm um desempenho claramente superior ao dos alunos do ensino privado subvencionado 
ou das escolas municipais, segundo as permanentes avaliações feitas para medir a qualidade da educação realizadas no Chile nos últimos anos.

6. Elas recomeçaram no mês de abril e continuam até o momento, sem previsão de terminar no curto prazo.

7. O sistema que atualmente vigora no Chile consiste no alistamento eleitoral voluntário, mas com a obrigatoriedade de

\section{Referências bibliográficas}

AGUILERA, Oscar et alii. 2006. La rebelión del Coro. Análisis de la movilización de los estudiantes secundarios. Santiago: Centro de Estudios Socio-Culturales (Cesc).

ANGELCOS, Gregorio. 2008. El cementerio de los muertos en vida. Santiago: Centro de Estudios Sociales Avance.

BRUNNER, José Joaquin. 2006. Brecha generacional, jornal El Mercurio, Caderno Artes e Letras, 11/6/2006.

CAMPIONE, Daniel. 2003.

Hegemonia e contra-hegemonia na América Latina. In: COUTINHO, Carlos Nelson (org.). Ler Gramsci, entender a realidade. Rio de Janeiro: Civilização Brasileira.

CARDOSO, Fernando Henrique \& FALETTO Enzo. 1970. Dependência e desenvolvimento na América Latina. Rio de faneiro: Zahar.

CEPAL. 1990. Transformación productiva con equidad: la tarea prioritaria del desarrollo para América Latina y comparecer às urnas para todos os alistados, salvo expressa justificativa por razões de saúde, viagem etc.

8. Aliás, a crise de representação dos partidos não é um fenômeno recente nem exclusivo do Chile, mas se insere nas transformações operadas nos regimes políticos da região e nas novas formas de fazer política (dimensão técnica/profissional).

el Caribe en los años 90. Santiago: Naciones Unidas.

CLAUDE, Marcel. 2008. Reforma educacional y fuentes de financiamiento. Site América Latina en Movimiento, http://alainet. org/active/ 25780

DAHRENDORF, Ralf. 1959. Clase y conflicto de clase en la sociedad industrial. México: Editorial Siglo XXI.

FERRETTI, Perina \& MASSARDO, Jaime. 2006. El mayo de los estudiantes secundarios.

Site Rebelión, http://www.rebelion. org/noticia.php?id $=34732$

GERMANI, Gino. 1979. Política y sociedad en una época de transición. Buenos Aires: Editorial Paidos.

GIDDENS, Anthony. 2005. Sociologia. Porto Alegre: Editorial Artmed.

HUNGTINTON, Samuel. 1968. Political order in changing societies. New Haven: Yale University Press.

INSTITUTO NACIONAL DE LA JUVENTUD. 2003. Cuarta Encuesta 
Nacional de Juventud, Santiago, INJUV.

- 2007. Quinta Encuesta Nacional de Juventud, Santiago, INJUV.

MATOS MAR, José. 1972. La dominación de América Latina. Buenos Aires:

Editorial Amorrortu.

MATURANA, Humberto. 2006.

Los jóvenes buscan darle sentido a sus vidas, jornal La Nación, 9/6/2006.

MOULIAN, Tomás. 2006.

El gobierno de Michelle Bachelet:

las perspectivas del cambio, Revista Observatorio Social de América Latina (Osal). Buenos Aires, Clacso, ano 6, n 19, p. 131-135.

PREBISCH, Raúl. 1971. Hacia una dinámica del desarrollo latinoamericano. México: Fondo de Cultura Económica. 1981. Capitalismo periférico, crisis y transformación. México: Fondo de Cultura Económica.
ROITMAN ROSENMANN, Marcos. 2000. Conflicto y crisis en el pensamiento social latinoamericano, Revista Observatorio Social de América Latina (Osal). Buenos Aires, Clacso, ano $1, \mathrm{n}^{\circ} 1$, p. 165-170.

SANT'ANNA, Julia. 2006. O que falta de social na socialista Bachelet?, Observador On-Line, Rio de Janeiro, Iuperj, vol. $1, \mathrm{n}^{\mathrm{o}} 7$, p. 2-13.

SANTOS, Theotonio dos. 2000. A teoria da dependência: balanço e perspectivas, Rio de Janeiro: Civilização Brasileira.

SEOANE, José \& ALGRANATI Clara. 2006. Los movimientos sociales en la geopolítica continental, Revista Observatorio Social de América Latina (Osal). Buenos Aires, Clacso, ano 6, $n^{\circ} 19$, p. 109-130.

\section{Resumo}

O presente artigo busca refletir sobre a forma como o governo chileno de Michelle Bachelet reagiu ao conflito desencadeado pelos estudantes secundaristas a partir de abril de 2006. Além de avaliar as reivindicações estudantis, pretendemos compreender o posicionamento expressado por alguns setores do governo e da sociedade política diante da emergência do conflito social. Propomos uma interpretação da atual experiência chilena e latino-americana a partir daquilo que chamamos de "hipergovernabilidade", quer dizer, um empenho excessivo em manter a governabilidade através da "solução antecipada" das demandas da sociedade. A análise das mobilizações estudantis respalda nosso argumento a respeito do temor que existe diante do conflito social, e da desmedida preocupação do Estado com a paz e a coesão social.

Palavras-chave: conflito social, governabilidade, participação democrática, movimento estudantil. 


\begin{abstract}
The following article is a statement about the way Chilean government reacted to the conflict raised by high school students practically along the whole first year of Bachelet's administration. Aside from trying to outline the causes which would be behind the erratic answer given by the authorities, the study intends to understand the position held by some of the sectors in government along with the political society in regard to the uprising of the social conflict. We think it is pertinent to build a new concept taking into account the Chilean and Latin-American experience. This concept is referred to what we call "hypergovernability", in other words, an excessive attachment to maintain governability by means of "anticipated solutions" of social demands. The current analysis of the various student movements indicates a fear, almost panic, in regard to social conflict, and a disproportionate concern of the State with peace and social cohesion.
\end{abstract}

Key words: social conflict, governability, democratic participation, student movement.

\title{
Résumé
}

Cet article est une réflexion sur la réaction du gouvernement chilien de Michelle Bachelet au conflit déclenché par les lycéens depuis avril 2006. On examine les revendications des étudiants, mais surtout on essaie de comprendre la position de quelques secteurs du gouvernement et de la société politique devant l'émergence du conflit social. On propose une interprétation de l'expérience vécue par le Chili et l'Amérique Latine à partir de ce qu'on appelle l'"hypergouvernabilité", c'est à dire, le souci excessif de maintenir la gouvernabilité par la "solution anticipée" des demandes de la société. L'analyse des mobilisations des étudiants soutient l'argument de l'existence de la peur du conflit social e d'un souci démésuré de la part de l'Etat de maintenir la paix et la cohésion sociale.

Mots-clés: conflit social, gouvernabilité, participation democratique, mouvement étudiant. 